\title{
Complexities, challenges and implications of collaborative work within a regime of performance measurement: the case of management and organisation studies
}

\author{
Emma Jeanes, University of Exeter \\ Bernadette Loacker, University of Lancaster \\ Martyna Śliwa, University of Essex
}

\begin{abstract}
The current demands on higher education institutions (HEIs) to become more efficient and effective have led to increasing performance pressures on researchers, and consequently on the practices and outcomes of researcher collaborations. In this paper, based on a qualitative study of collaborative experiences of management and organisation studies scholars, we explore the complexities and challenges of researcher collaborations under the current regime of academic performance measurement. Our study suggests that researcher collaborations are underpinned by four main rationalities: traditional-hierarchical, strategic-instrumental, scholarlyprofessional and relationship-orientated. We find that strategic-instrumental rationalities are the most prevalent and typically infuse other rationalities. Our research demonstrates that there are potential adverse consequences for the quality and purpose of outputs, the effects on collegial relationships and risks of exploitation and reinvoked hierarchies in collaborative relationships. The study reveals some of the problematic implications for academics and HEIs that emerge as a consequence of research productivity measurement.
\end{abstract}

Keywords: Academic hierarchy; Business Schools; New Public Management; researcher collaboration; research performance measurement. 


\section{Introduction}

Across the world, higher education institutions (HEIs) have been undergoing transformations intended to make universities more entrepreneurial, market-oriented, managerial, accountable and productive (e.g. Davies and Thomas 2002; Nikunen 2012; O'Connor and O'Hagan 2016). Governments in a number of countries have introduced periodic research audits aimed at improving universities' competitiveness and efficiency in their use of resources. Arguably, academics have never before so strongly experienced performance pressures (Adcroft and Taylor 2013; Clarke and Knights 2015; Ylijoki 2013).

These transformations have been underpinned by the gradual withdrawal of state funding for higher education (HE) and an increasing requirement for universities to generate their own financial resources, combined with New Public Management (NPM) inspired reforms, such as the introduction of academic performance management. These have impacted academic practice and the ways in which academics relate to their work and to each other (e.g. Deem, Hillyard and Reed 2007; Ylijoki, 2013), and have led to a literature analysing the consequences of increased demands on academics (Bogt and Scapens 2012; Cadez, Dimovski and Groff 2017) to demonstrate high productivity (De Vita and Case 2016; Gill 2014). In particular, there has been a growing body of work addressing the multi-faceted implications of academic performance measurement, especially research productivity evaluated through criteria such as publication ranking and success in attracting external grants (Leišytė 2016; Shore and Groen, 2009).

This paper contributes to the critical literature on NPM in HE, and specifically on the impacts of research productivity measurement. It does so through addressing the complexities, challenges, inherent power struggles and implications for academics and HEIs of researcher collaboration (Berman 2008; Leahey and Reikowsky 2008; Smith, 2001). The subject of researcher collaboration - understood with regard to a relationship between researchers, rather than, for example, researchers and research participants or other stakeholders (Engstrom, 1984) - has previously been explored in relation to motivations for, and patterns and strategies in, collaborative relationships (Jeanes, Loacker and Śliwa 2014; Morrison, Dobbie and McDonal 2003). However, the implications of collaboration for researchers at different career stages and for academic practice in general remain under-explored. This is partly due to the fact that studies of researcher collaboration, especially those conducted in the medical and natural sciences, have typically adopted bibliometric approaches consisting of quantitative 
measurement of different collaboration-related variables (Birnholtz 2007; Knobel et al. 2013; John-Steiner 2000). As such, they have not addressed the more complex and challenging aspects of collaboration that do not easily lend themselves to measurement.

To complement existing debates on research productivity measurement and researcher collaboration, our paper draws on a qualitative study of collaborative experiences of academics in management and organisation studies (MOS) at different career stages within three institutional contexts, namely British, Germanic and Nordic. These contexts have undergone NPM-inspired reforms, with an emphasis on research productivity which is now a common feature of university management across Europe (Barrett and Barrett 2011; Leišytè 2016; Musselin 2005). In the analysis we identify and critically examine four rationalities, understood as 'ways or systems of thinking' (Gordon 1991, 3), inscribed in and underpinning accounts of collaborative practices. We discuss the consequences of researcher collaboration under conditions of research productivity measurement for academics and HEIs with reference to these collaborative rationalities. The following sections present, respectively, a brief overview of key relevant arguments from the literature on research productivity measurement and researcher collaboration, an outline of fieldwork methods, an analysis of the empirical material, and a discussion.

\section{Research productivity measurement in contemporary academia}

The term New Public Management typically refers to a set of reforms initiated in the 1980s and involving the introduction of management methods previously applied in private sector organisations to the public sector, with the intention of making the latter competitive, more efficient in its use of public resources and more effective in delivering goods and services (Christensen and Lægreid 2007). In HE, NPM has come to be associated with discourses of excellence (in research, and more recently in teaching), relevance and accountability, and managerial approaches to monitor and evaluate the work of academics according to a variety of performance criteria (Davies and Thomas 2002; Deem, Hillyard and Reed 2007). While such discourses and modes of managing have been widespread across all university disciplines, schools of management and business are often considered as characterised by a remarkably 'heavy presence of managerialism' (De Vita and Case 2016, 354), which makes them a particularly apt setting to study the impacts of NPM on academia.

Critics of academic performance management, and especially research productivity measurement, have highlighted that it gives rise to individualistic behaviours and practices, 
reinforcing competitiveness and potentially undermining collegiality (Ball 2012). Lynch (2015, 1999) warns that those who have internalised the productivity imperative are likely to develop an 'actuarian and calculative mindset', and to adopt a way of relating to the university organisation and to other academics, including collaborators, in purely transactional, careeroriented terms.

Amongst specific practices impacted by research productivity measurement, a recent study by Nygaard $(2017,529)$ has identified those associated with 'decisions about what to produce, how high to aim (including how to know when something is finished), whether and how to co-author, and what to prioritize'. Academics are expected to focus on the production of publication outputs that 'count' within a research measurement regime, which in MOS primarily means highly ranked academic journal articles. Different institutions and contexts develop their own journal rankings - such as the Chartered Association of Business Schools' Academic Journal Guide (CABS 2015) widely used in the UK- which 'are applied by (university) managers to assess and direct staff' (Willmott 2011,437) and influence and predict performance outcomes. This incentivises collaborative publications since both quality and quantity of output matter for assessing research productivity and can even impact global rankings. ${ }^{i}$ However, questions have been raised about the quality of outputs produced under the regime of 'excellence'. For example, it has been argued that as a result of these measurements, academics might be more concerned with producing publications that conform to external quality evaluation criteria rather than striving to produce what they consider their 'best work' (Nygaard 2017). Following Willmott $(2011,437)$, the increasing predominance of journal lists and rankings as performance measurement tools tends to exert a 'homogenizing impact', stifling scholarly diversity and innovation. A specific study of management scholars has further shown a tendency to approach writing for academic publication as a 'game' rather than a process of critical inquiry (Butler and Spoelstra 2014).

Not being able to satisfy research performance (typically publication) expectations can have detrimental effects on academics, manifested in feelings of insecurity and other negative thoughts, which in turn affect an individual's ability to produce further publications (Clarke and Knights 2015; Sherry et al. 2010). This can lead to an individual's inability to secure academic employment, to remain employable or to gain promotion. Such far-reaching personal impacts have been found to particularly strongly affect women and early career researchers (ECRs) (Davies and Thomas 2002; Laudel and Gläser 2008; Leišytė 2016; Nielsen 2017; Ylijoki and Henriksson 2017), and add to the appeal of researcher collaborations. 


\section{Complexities and challenges in researcher collaborations}

Katz and Martin $(1997,7)$ describe researcher collaboration as 'the working together of researchers to achieve the common goal of producing new scientific knowledge'. More broadly, collaboration is commonly considered a vehicle for building professional networks, sharing knowledge, ideas, skills, experiences, workload, resources and risks associated with the research process, and for improving future employment prospects as well as attracting research funding for the collaborating parties (Bammer 2008; Bozeman and Corley 2004; Ritchie and Rigano 2007). Existing literature generally views collaboration as a positive and desirable aspect of the research process (Cheek 2008), one that brings about greater creativity in individuals (Smith 2001). Collaboration is also understood as a way to counter the feeling of loneliness in research with a sense of solidarity, friendship and enjoyment (Katz and Martin 1997; Shore and Groen 2009).

Researcher collaboration can, however, also lead to feelings of disappointment, resentment and anger (Ritchie and Rigano 2007). Collaborations can be messy, since collaborative relationships involve two or more individuals 'with potentially contrasting viewpoints, interpretive frameworks, personal characteristics, histories, and experience, that all contribute to knowledge production' (Thomas et al. 2009, 313). However, there is more to understanding collaborative relationships than can be captured by the idea of individuals working together, since researcher collaborations are embedded in a broader politico-economic and institutional socio-discursive context. Historically, a key element of this was the 'hierarchical social system of science', which manifested, among other things, in 'dependency, financial or intellectual' (Beaver and Rosen 1979, 232), particularly of junior researchers on senior ones. This situation of institutional and personal dependency, that still exists today, can result in practices disadvantaging the more vulnerable collaborators. Examples of these practices include the 'Matthew effect' (Merton 1973), where greater credit for joint work is attributed to the more eminent researcher in the collaborative partnership regardless of the actual extent of their contribution, and the 'Matilda effect' (Rossiter 1993), where contributions by female researchers are not acknowledged and/or are attributed to her male colleague(s).

The power inequalities associated with institutional hierarchies and differences in career stage can result in unequal influence on decision making, and/or shaping the final 'product' of collaboration (Melin 2000). For junior researchers, working in a hierarchically structured, 
'vertical' (Morrison et al. 2003) team might denote a formal reporting relationship with the senior academic, rather than co-operation and an ability to express one's 'voice', even though they may make a substantial contribution to the research. Even in 'horizontal' (ibid.) relationships, i.e. those where the collaborators are broadly equal in status and/or may be personal friends outside the work setting, there is a risk of imbalances in power, manifesting in ‘impositional tendencies' (Lather 1991) or even 'conceptual imperialism' (Stanley and Wise 1983 ) being exercised by one party over an/other(s).

In the context of an academic performance measurement regime, not only do pressures on research performance present drivers for increased collaborative activity, they also influence the choices and practices of collaborators. It is therefore crucial to explore whether and how the present context impacts individuals as well as collaborative practices and outputs associated with researcher collaborations. In the remainder of this paper, we empirically address the complexities and challenges of researcher collaborations experienced by management and organisation studies academics.

\section{Methodology}

\section{Data collection and analysis methods}

Fifteen interviews (seven men, eight women) were conducted with Early Career Researchers (ECRs, $n=6$ ), Mid-Career Researchers (MCR, $n=6$ ), and Senior Career Researchers (SCR, $n=3$ ) to reflect a breadth of research experience and effects of levels of seniority on collaborative practice. All participants were employed in business or management schools, in one of five countries: Austria, Denmark, Germany, Sweden and the UK, representing three broader academic contexts: British (BC, $n=5)$, Germanic $(\mathrm{GC}, \mathrm{n}=5)$ and Nordic $(\mathrm{NC}, \mathrm{n}=5)$. The aim was to include different regional and institutional environments in Europe affected by NPM and productivity measurement in order to reflect some of the diversity of the academic contexts without seeking to present a comprehensive picture of different European systems or provide a representative comparative study. Most participants had experience of more than one context and of inter-institutional and international collaborations, therefore classifying participants based on their current employment can only be seen as a guide (see Table 1). This diversity enables us to explore experiences beyond, and therefore irreducible to, a specific national or institutional context. The specificity of the field of study, which limits broader cross- 
disciplinary analysis, and the inclusion of those with prevailing performance management regimes, makes it possible to focus on those facing similar discipline-specific challenges.

The semi-structured interviews explored questions around: 1) the institutional context in which participants were employed; 2) participants' understandings of academic work and specifically researcher collaborations; 3) reasons for researcher collaborations; 4) experiences of researcher collaborations including both successful and unsuccessful collaborations; 5) practices of collaboration; 6) challenges and costs, as well as benefits and value of collaborations; and 7) reflections on researcher collaborations. Each interview, undertaken by a member of the international research team (all of whom had experience in at least two of the selected contexts) was recorded and transcribed. For the purposes of anonymity we refer to the participants using pseudonyms throughout the analysis, indicating their position and employment context.

Participants were selected through a stratified purposeful sample taken from a wider study, which drew on our broader research networks, to incorporate academics from the three contexts, and a balance across the genders, and across seniority, with a deliberate bias towards early and mid-career researchers to reflect the profile of the academic workforce. Determining the position of potential participants in the selection process was based on a number of factors including job title and length of service, with the former being the most significant factor. Classifications were agreed amongst the research team (see Table 1).

Add Table 1 here

The empirical material was analysed iteratively, with each member of the research team exploring the data to draw out themes, which were then discussed and agreed. Initially we categorised the data by four meta themes that broadly reflect the interview topics, resulting in 56 subthemes. Across these themes we identified underpinning rationalities that sustained, justified or explained motivations, attitudes, practices, experiences and responses to the context. Of these we agreed there were four meta rationalities which we use to present the findings. Whilst individual stories were unique, there was significant consistency in the rationalities recurring in the interviews, leading us to consider the findings to be robust. Career stage was an important factor in our analysis, and gender differences were also evident but less strongly 
so. We therefore do not draw out the gender-based arguments in this paper, given the need to be focused in our analysis.

\section{Background to empirical contexts}

The three regional contexts in Western Europe from which we have drawn our sample of participants have all undergone NPM reforms and are characterised by cultures of academic performance management and research productivity demands. In all of them, universities are expected to compete against each other for resources, staff and the 'best' students, and to operate in an efficient manner. Here, schools of business and management lead the way in terms of 'student-centricity' and demands for 'financial sustainability' and 'commercial orientation' (De Vita and Case 2016, 354; Kallio et al. 2015). Schools of management and business, in particular, are subject to international comparisons through accreditation and ranking (Engwall, 2007).

The British academic environment, and in particular that of business schools, is commonly seen as one within which the culture of performance management is particularly strong (Chubb and Watermeyer 2017). Since 1986, HE has been subject to periodic evaluations to assess the quality of research and determine funding. These have been key in shaping the norms of the sector, which make an explicit link between quantity of so-called 'high-quality' publications of academics and levels of government funding provided, as well as an institution's place within national and international rankings (Leathwood and Read 2013). The effects have significant career and behavioural implications for individuals, whereby the generation of highly ranked publication outputs becomes the main rationale and career strategy of academics, as it is more likely to lead to promotion than other types of academic activity (see also Fernando 2016).

Similarly, an emphasis on efficiency and competition dominates the Germanic academic context, which includes HE institutions located in Austria, Germany and Switzerland (MüllerCarmen and Salzgeber 2005). The performance of universities is regularly evaluated through audit instruments and performance targets (Leistungsvereinbarung) between the university and the state (Welte, Auer and Meister-Scheytt 2006). Traditionally, a unique cultural feature of the Germanic academic context was a system of professorial patronage and patriarchal relations associated with the 'chair regime' (Müller-Carmen and Salzgeber 2005). While this system, with its hierarchical inequalities, is still influential, HE reforms in the Germanic context have led to increased numbers of mainly ECRs and MCRs being employed on temporary, short-term and often third-party funded contracts (Sander 2012). 
As with the Germanic environment, universities in the Nordic context, with institutions based in Denmark, Finland, Iceland, Norway and Sweden, are largely funded by tax revenue and regulated by agreements between the state and the institution, rooted in the principle of $\mathrm{HE}$ sector's autonomy (Aarrevaara, Dobson and Elander 2009). Nevertheless, academic performance management and research productivity pressures have a strong presence in the Nordic context. This is not only because of NPM reforms and the adoption of business management models, but also because of Nordic institutions' ambition to be amongst the most highly ranked universities in the world (Engwall 2007).

Below we present an analysis that identifies common themes across the three regions in relation to the challenges, complexities and power struggles within researcher collaboration, taking particular account of the career stages of our participants, which was identified as a key differentiating factor.

\section{Rationalities in researcher collaborations}

A variety of rationalities inform prevalent practices of researcher collaboration. Below we critically discuss these rationalities, which we term as: a) traditional-hierarchical, b) strategicinstrumental, c) scholarly-professional, and d) relationship-oriented.

\section{Traditional-hierarchical rationalities}

Participants' narratives suggest that researcher collaborations remain underpinned by traditional-hierarchical rationalities, whereby emphasis is placed on the seniority and institutional position of collaborators. Most academics share similar understandings as to who makes a 'good' collaborator, such as equal and meaningful contributions (for example, going beyond providing access to a network) and reliability. On closer inspection, however, responses often differ with respect to hierarchical position. Junior colleagues only occasionally mention benefits gained from collaborations with senior scholars, arguing, instead, that inequality (e.g. of contributions and voices), power asymmetry, and exploitation were integral to collaborations. In particular ECRs employed within the Germanic context tend to refer to their institutions as being hierarchically ordered. As one participant indicates: "more than $99 \%$ of the collaborations are kind of decided for me... [by] a well-known person in the community" (Karl-ECR-GC). Elsewhere in the interview, the same participant comments on a situation 
where a senior collaborator, "never wrote a single line for a publication. This just has to be accepted because of the hierarchical system in Germany and Austria”. This experience was shared by others in different contexts:

"[E]ven though his name (senior collaborator) is last in the alphabet, he puts his name first ... I've tried to address it but there's been no response. So you kind of feel like the hierarchy has been slipping in... I didn't really know how to handle that" (Peder-MCRNC).

These "less mutually collaborative research teams that come together more because of employment and institutional relationships" (Louis-MCR-BC) were widely evident. Such tolerance for inequality results in systematic burdens and challenges placed on those lacking an established institutional position, who are compelled to collaborate (see also Morrison et al. 2003).

Unbalanced 'position power' (Macfarlane 2017) and hierarchy sustain a collaborative culture of discomfort, insecurity and anxiety which limits the scope for developing scholarly ideas. James, for example, struggled with a $\mathrm{PhD}$ examiner who became his boss and felt he had "some ownership" of James' thesis, referring to "our paper (to) which he contributed nothing aside from a few comments". In the end, James refused but also abandoned the intention to publish from his $\mathrm{PhD}$ to avoid conflict, also noting:

"It's not a really good position to have as he's an editor of a journal and he's... situated in a social network of great power" (James-ECR-BC).

Where seniority-based collaborations have been experienced as problematic, some researchers have developed a 'calculative mindset' (Lynch 2015) towards collaborations:

“I avoid working with big names... they wouldn't be putting any effort in and would be taking all the glory... I would now be very upfront about expectations, about ownership of this, that and the other, so I would almost go in it with a semi-legal head on: this is what is going to happen; this is who owns the data, this is what your contribution will be" (Sally-MCR-BC). 
While some are sceptical about the benefits of collaborating with senior academics, others point to the longer-term advantages of such collaborations that also hint at a strategic rationality and reflect the pressures for publication (Nygaard (2017):

"Maybe you should join a senior researcher first in order to get published, and then you are within the circles and then you try to get more established" (Edward-MCR-GC).

"Career-wise, proximity to senior scholars is still very important for me... You won't get published, if you don't have a network" (Agneta-ECR-NC).

In contrast to ECRs, senior academics stress their mentoring role towards junior colleagues who "are dependent on you" (Philip-SCR-BC), which manifested in contributing to collaborative efforts and in working with ECRs "to help them develop their career" (Danika-SCR-BC). Their views of hierarchy and the associated inequality of contribution in collaborations tend to be less disapproving, as illustrated by Georg's quote below:

"I have the classic history of the younger scholar who will do more work than the professor he publishes with... Of course, one of the questions is whether I am becoming that too myself... now that I am a tenured full professor, I'm kind of edging towards the same role I guess, by way of my trajectory... Maybe it's also ok this way, I don't know... tricky" (Georg-SCR-GC).

Georg also gives examples of specific practices he engages in to benefit junior colleagues, such as putting first on a paper the name "of the one who needs it" (Georg-SCR-GC), and argues for a critical appraisal of the different consequences of institutional power and hierarchy, which he also believes he may now be complicit in sustaining.

Another senior scholar advises junior researchers to frame the inequality of collaborations informed by hierarchical rationalities in positive terms:

"Work with the best people you can... learn a lot from that... Be cognizant if you're being exploited, but also questioning your own ideas about what it means to be exploited... because I think sometimes it's learning" (Philip-SCR-BC).

These responses indicate how unequal relations can be perpetuated and justified despite some of the SCRs also reflecting on how they experienced and suffered from unequal collaborations as ECRs. 


\section{Strategic-instrumental rationalities}

There is a sense among all participants that collaborations are an institutionally expected norm (Berman 2008). Many participants argue that "it would raise eyebrows" (Christine-ECR-BC), or even be accompanied by "informal sanctions" (Eva-ECR-NC), if one did not comply with the "pressure to collaborate" (Odette-MCR-GC). Several of the interviewees relate institutional collaboration norms to strong demands for performance- and output-orientation and strategic thinking and practice (Clarke and Knights 2015; Lynch 2015). While being "strategic" is often denied, the narratives show that instrumental rationalities underpin practices of researcher collaboration regardless of institutional context.

When asked about the reasons for researcher collaboration, participants often refer to "collaborators offer(ing) something you can't" (Louis-MCR-BC), the "pooling of competences and resources" (Odette-MCR-GC), and "combining of fields of expertise" (Karl-ECR-GC). Collaborations are seen to make scholars more "efficient" (Louis) and to "get more things done" (Katharina-ECR-GC) in a context where scholars are "so time-conscious" (Suzanne-MCR-NC) that, in some instanes, face-to-face meetings are replaced by, digitally supported, "distance collaboration" (Agneta-ECR-NC). The key role of instrumental rationalities is further revealed by practices such as "name dropping" and seeking "big names" (James-ECR-BC) in collaborations, reinvoking hierarchies. Especially ECRs and MCRs note that "trophy-hunting collaborations" (Odette) can be "very important for one's career" (Agneta-ECR-NC), and in extremis can involve strategies of "find(ing) an American professor" to "get to the American journals" (Katharina). "Mutual benefits" (Georg-SCR-GC), such as a willingness to bring to the collaboration one's experience and reputation in exchange for empirical material are also mentioned, especially by more established researchers.

Interestingly, however, purely transactional collaboration practices are mainly ascribed to others (and in particular to UK-based colleagues and institutions (DeVita and Case 2016)) rather than oneself, as exemplified by the following quote:

"I've heard of colleagues who have included another very well-known author because this raised their publication chances... I don't know if I want to apply [this strategy], but it seems to work" (Karl-ECR-GC). 
Participants commonly argue that it is the contemporary 'academic climate', underpinned by performance management pressures, that makes strategic-instrumental considerations and, concomintantly, a short-term outlook in collaborations necessary (Smith 2012):

"I have to work on projects that will not last for years without any output. We are forced to think like that" (Karl-ECR-GC).

While performance pressures tend to increase the need for ECRs to take on potentially exploitative collaborations, the narratives suggest that peer-peer collaborations can also be affected by these pressures, such as balancing speed of publication with journal ranking, leading to some adopting a formal-contractual or "explicit approach" (Louis-MCR-BC) to collaborations to agree objectives and minimise the "risks of being used" (Agneta-ECR-NC). Challenges are also faced when collaborators have conflicting needs - such as James (ECRBC) who needed a 'quick' publication for his probation, whereas his collaborator wanted to take his time and target a 4-rated journal.

There are also justifications of output-oriented rationalities on intellectual grounds that draw upon NPM notions of efficiency and accountability:

"Maybe there's nothing wrong with [output-orientation]... If we believe that publishing is a way to get the best ideas out into a public format so that they can do some good, then okay, why not streamline and bring the best people together and make the process really efficient" (Eva-ECR-NC).

Furthermore, strategic rationalities are often portrayed as imperative, especially for junior researchers who have not (yet) secured stable employment, particularly under the "pressure to produce papers in certain journals" (Odette-MCR-GC) (see also Ylijoki and Henriksson 2017).

But the strategic-instrumental collaborative rationalities are also seen to lead to a reduction in scholarship, quality, originality and novelty (Nygaard 2017), or the corrosion of 'scholarly competence' through efficient processes of producing highly ranked publication outputs (Willmott 2011):

"People are forced to strategically map the collaborations - that might become a little sick if it's just about the journal ranking or the list of publications... The ranking encourages a superficial take, first of all, and a very instrumental take on bodies of thought. It's this kind 
of approach that dominates collaborations, and that's sad.... [Many collaborations] cannot be innovative. It is not rewarded. Creativity is not rewarded... [What] remains [are] sort of dull collaborations." (Georg-SCR-GC).

"In my main collaboration I come up with the ideas and the data. I do the conclusions and (my collaborator) does the literature... I do worry that my reading of the literature... has become more superficial because I know somebody else is doing a damn good job on it... I worry that my ability to craft a good literature review is deteriorating" (Sally-MCR-BC).

The strategic instrumental rationality best exemplifies the effects of strong performance management and measurement cultures on academics, their collaborative practices and collegial relations.

\section{Scholarly-professional rationalities}

Several of the narratives, across all career stages, suggest that collaborative practices and relations are driven by scholarly curiosity, the development of common interests and understandings, "intellectual discussion" and "learning" (Philip-SCR-BC). While perhaps idealising researcher collaborations, they show that strategic-instrumental rationalities, even if predominant within many collaborations, are not exclusive or determining. Participants argued that publications were secondary to "solving an interesting problem or being with interesting people, sharing information" (Eva-ECR-NC) and "getting an idea that you have on paper" (Peder-MCR-NC).

It is not unusual for researchers to portray collaborations as a means for scholarly-professional and personal development:

"What I love most about being an academic is that opportunity to have deep, meaningful and powerful conversations with other people, and the challenge and the critique and the learning from others and the inquiring with others, and getting interesting perspectives... It enriches... what it is that's of value in what I do" (Christine-ECR-BC).

Although some assumed that scholarly-professional rationalities were not occurring in the UK:

"There are two different understandings of research. The first thing is that you provide your career with papers and the other thing is fulfilling your ethos as a researcher: that you try to find out something and you are really burning to learn... This is similar with Austria and 
Sweden, but with someone from the UK, it's more in the direction of a publishing industry... In other countries... you have a more research-oriented choice" (Edward-MCR-GC).

Many narratives reflect contestation and ambivalence regarding academic work being an end in itself or a means to an end. Indeed the participants often promote an understanding of researcher collaboration as being simultaneously about pursuit of ideas and scholarly development, and efficiency and output, as illustrated below:

"I do want some output of my collaborations... And it has often been (that) a collaboration is starting with a publication. But it's also for my personal gain. I learn through working with others. I just think it is really a great experience... I have never entered a collaboration because I think that I end up getting a publication" (Agneta-ECR-NC).

While attempts to mobilise collaborations for individual and collective development and learning are evoked by some participants, they do not always seem to prosper. In several instances, collaborations, despite aiming for the promotion of 'multiple voices' (Smith 2001), result in a reduction and homogenisation of voices and creative ideas in which the mutual adjustments to encompass the thoughts of the collaborator lead to "a more average paper in the end" (Edward-MCR-GC). As we have seen above, hierarchies can also challenge scholarly rationalities.

\section{Relationship-oriented rationalities}

The narratives suggest that many collaborations are underpinned by an aspiration and desire for a 'culture of friendship' and 'ethics of care', invested by mutual support and help, that challenge purely instrumental collaborative rationalities (Nygaard 2017). This is especially evoked where researchers speak about the similarities between collaboration and friendship, "trust" (PederMCR-NC), "love" and "marriage" (Danika-SCR-NC), thereby emphasising that collaborations can be "like duet(s)" (Danika), often borne out of "long-term relationships" (Odette-MCR-GC).

The following excerpt, addressing the journal publication pressures that ECRs face, illustrates how a friendship-based collaboration helped a scholar to secure continuity of employment:

"The Dean of the School... basically told me that if I didn't produce [papers] in two 'three star' journals in the next year, I didn't have a job... [One of my colleague-friends responded:] we want to make sure you have some job security. Let's come up with a topic, and write a 
paper and target just a mid... two/three star journal... That was a wonderful collaboration where somebody saw that I was in need and really helped me out"' (James-ECR-BC).

While this account can be read as an illustration of mutual support and friendship within collaborations, it also demonstrates instrumentality-invested rationalities and specifically how individualised performance measurement, exemplified here by the REF in the UK, (re)shapes collaborative practices and rationalities (Cheek 2008) and the purpose of research more generally. The interconnectedness of relationship-focused and strategic-instrumental rationalities is also evident in accounts claiming disciplining effects to be a key positive consequence of researcher collaborations, as illustrated by a participant declaring that "collaborators keep me honest - I owe someone something" (Eva-ECR-NC), and similarly a personal relationship can be seen to guarantee that the collaborator "will feel a greater responsibility for contribution" (Suzanne-MCR-NC) and will contribute at an "adequate level" (Edward-MCR-GC).

While collaborations could be experienced as joyful and enriching they can also be accompanied by multi-faceted personal and professional dependencies and inequalities, such as where someone has "their ideas as number one" (Philip-SCR-BC), which can damage the relationship upon which the collaboration relies. The "fading away" (Georg-SCR-GC) or “dissipat(ion)" (Louis-MCR-BC) of problematic relations can, like damage to friendships, not always be prevented. The following excerpt offers an insight into the vulnerabilities, dependencies and pain that can emerge from long-term collaborations:

"It was someone very, very close to me, and this was much more difficult to handle... I challenged her and she couldn't take it at all... She was really very cross, angry and very hurt. We were involved in huge projects at the time, we had a half million pound research grant, we had a number of ongoing papers, conference presentations, and it was very difficult to disentangle from that... I walked away from it all, really... It's like if you're having a romantic relationship... and then saying something which is so hurtful that there is no going back, you can't undo it” (Sally-MCR-BC).

Individual conflict and ambiguity over what should be done when friends do not contribute reflect the contested notions of contribution and ownership of ideas that often remain in place and echo experiences of traditional-hierachical rationalities: 
"I wanted to be involved with (collaborator) because she did fire me up with her energy and ideas, and I felt we had a connection, intellectual, emotional... But it ended up being a very protracted, painful process; very unsatisfactory. It felt extremely unequal, very unbalanced... So, when someone hasn't contributed enough, at what point is it a joke really to even leave their name (on a paper)?" (Christine-ECR-BC).

Yet our researchers often tolerated inequalities exactly because of friendship, and it was uncommon for these to be explicitly addressed. Silence about these concerns is sustained by a number of factors of both personal and professional nature: the personal costs involved in speaking out, perceived lack of institutional support making it "very difficult to hold someone to account for non-performance" (Christine-ECR-BC), as well as the risks to networks where there are "people who don't speak... around the country because of these damaged relationships" (Sally-MCR-BC). Practices that are ethically problematic in a professional context are glossed over as dissatisfied collaborators convince themselves that "this is just a paper" (Eva-ECR-NC), and therefore it is preferable to "let things go" (Philip-SCR-BC).

\section{Discussion}

A range of observations and implications with regard to collaborative and individual academic practices, as well as relationships within the academic community and HEIs emerge from our study. The empirical material shows that researcher collaboration, and how institutional research performance pressures shape collaborative practices and relations, are all but taken for granted (Katz and Martin 1997). Specifically, the study provides insights into the complexities and challenges of collaborations that are informed by four rationalities, which are sustained by both institutional discourses and norms of academic performance management and the specific dynamics immanent to collaborative practices and relations.

Our study has aimed to address collaborative experiences and practices beyond a focus on coauthoring and publishing. However, the accounts of the MOS academics we interviewed suggest that the main understanding and focus of collaborations is on the production of highly ranked publications and, specifically, journal articles rather than, for example, funding applications or the scholarly project itself. As such, the 'publish or perish' imperative can be seen as the key aspect of academic performance evaluation in business and management schools. Even collaborations with emphasis on relationships and scholarly interests were often 
subsumed by, or only feasible because of, their output-generating potential, although there was the belief that the British academic context was the most extreme in this regard. However, output generation in highly ranked journals was commonly not seen in the quality-ascribed sense of scholarship, hinting at the adverse effects of pressures to publish on output quality and the purpose of research, collaboration and knowledge production (Nygaard 2017). Rather than collaborations achieving greater creativity (Smith 2001) and pluralism, under the current regime of academic performane measurement, it is likely that collaborative practices foster a scholarly 'monoculture' (Willmott 2011, 429) and thus lead to narrow, incremental, often self-referential and superficial projects being embarked upon - i.e. ones that are seen to hold the promise of bringing highly evaluated, quantifiable and thus 'excellent' outputs, and contributing to researchers' career progression.

This output-orientation in relation to the main objectives of collaborations reflects a broader observation stemming from our study in that strategic-instrumental rationalities underpinning collaborations were the most widespread in our sample of participants. This demonstrates that, in a 'partnership or perish climate' (Berman 2008, 167), strategic-instrumental considerations tend to suppress other collaborative rationalities such as those focusing on scholarly activities, projects and relationships. Even where academics claim a relationship- and friendship-based 'ethics of care' and 'gift giving' to be core to collaborations, they simultaneously express an instrumental approach to collaboration and, specifically, an underlying need for the creation of 'added value' (Macfarlane 2017) through publications. The study hence suggests that individualised research performance pressures support and sustain the emergence of certain types of (instrumentally-oriented) friendships and alliances. Such an instrumental orientation can pose a challenge to amicable relationships and - due to the potential for tensions and conflicts to arise as academics pursue the objectives they are individually assessed against can be seen to promote separation among management scholars (Harvie 2004; Lynch 2015). This is a problematic and somewhat paradoxical effect of the performance measurement and management regime dominating contemporary HEIs (see also Butler and Spoelstra 2014).

The dominance of strategic-instrumental rationalities and practices in researcher collaborations notwithstanding, most participants were keen to eschew them personally or relate them to regulative performance measurement instruments, such as journal lists and rankings, and associated discourses prevalent in management and business schools (De Vita and Case 2016). They distanced themselves from the new 'archetype' of the modern strategic, careerist scholar, who uncritically conforms with research output and productivity demands (Clarke and Knights 
2015). As a result tensions between scholars' professional values and identity, and their performance and career success, were evident.

However, rather than engaging in self-reflexivity about one's own role, scholars at different career stages drew on it to explain and justify their actions in contradictory ways - such as the different understandings of what constitutes a contribution. While SCRs consider their patronage to ECRs in terms of support and generosity, ECRs perceive their disproportionate contribution to a project as a manifestation of inequality which they frame in terms of unavoidable, temporary exploitation and/or necessary 'career investment' given the increasing pressures on performance. Formal hierarchies - particularly outside of the Germanic context have sometimes been replaced with new dependencies and reinvoked hierarchies that are oftentimes self-imposed in order to secure employment (Laudel and Gläser 2008; Ylijoki and Henriksson 2017).

Problematic collaborative practices and relations are however not limited to 'vertical' collaborations (Morrison et al. 2003). As our findings illustrate, struggles over power are likely to occur irrespective of the collaborators' career stage and position relative to each other. The study suggests that strong performance cultures in HEIs tend to encourage academic malpractices, delineated by a lack of contributions, reliability, mutual responsiveness, trust and, thus, a lack of collegiality and engagement within collaborations. Such practices obviously counter notions of scholarly responsibility - to one's colleagues, community and the field of study. Indeed scholarly responsibility appears to be replaced by a sense of institutional accountability, mainly defined by meeting performance targets and metrics. The management scholars interviewed, however, do not or not effectively question prevailing institutional discourses and norms around productivity and scholarly accountability. In the absence of such critical reflexivity (Cheek 2008), researchers' individual and collaborative practices tend to perpetuate and reinforce the performance management regime within management and business schools and academia in general (Clarke and Knights 2015). While we do not wish to glorify academic cultures of the past, our study demonstrates that current performance and research productivity pressures in HEIs 'crowd out' some important academic values and ideals, such as the pursuit of research out of scholarly curiosity and an aspiration for critical inquiry, and the cultivation of diverse and mutually supportive collegial relationships - in support of an unquestioning acceptability of demands for strategic, output-oriented and career objectivesdriven academic practices. 


\section{Conclusion}

This paper contributes to the critical literature on NPM in higher education by addressing the complexities, challenges and implications of researcher collaborations for academics and HEIs (Leišytė 2016; Ritchie and Rigano 2007). Through analysing the narratives of management scholars across seniority based in different institutional contexts in Western Europe, it has considered the effects of performance management, and in particular research productivity pressures, on researcher collaborations. The findings demonstrate the multi-faceted consequences of the contemporary 'publish or perish' regime and the discourses it promotes, which inform both the choices behind the formation of collaborative relations and the practices of researcher collaborations. The study identifies four, often intertwined, rationalities, namely: strategic-instrumental, traditional-hierarchical, scholarly-professional and relationship-oriented rationalities, and the dominance of strategic-instrumental rationalities.

The strategic-instrumental rationalities tend to suppress and 'crowd out' other collaborative rationalities and thereby highlight most notably the fundamental challenges faced by academics in pursuing scholarly practice under pronounced research performance pressures (Nygaard 2017), adding to the impression that intellectual curiosity and passion, a preparedness to take risks and a willingness to devote energy to intellectual challenges for their own sake are not seen as being at the heart of scholars' professional values (Butler and Spoelstra 2014; Willmott 2011). Instead we see the ascent of the opportunistic, career-driven scholar who cultivates strategic, low-risk high-output collaborations, which may foreclose more interesting, inventive and valuable forms of research and jeopardise collegial relationships informed by critical reflexivity, equality and mutual trust (Cheek 2008). While we do not argue against the aspiration to produce high-quality research, our study of researcher collaborations among MOS academics underlines that the (un)intended consequences of the prevailing performance management regime and its emphasis on efficiency, excellence, relevance and accountability are far-reaching, for academics and for HEIs. 


\section{Note}

${ }^{\mathrm{i}}$ The CWTS Leiden Ranking exemplarily illustrates this point. The Leiden Ranking is a global university ranking based on bibliometric indicators. The number of academic collaborations with other universities and industry - is, next to citation impact, the key indicator underpinning this global university ranking (CWTS Leiden Ranking 2017).

\section{References}

Aarrevaara, T., I.R. Dobson, and C. Elander. 2009. "Brave New World: Higher Education Reform in Finland.” Higher Education Management and Policy 21(2): 1-18.

Adcroft, A., and D. Taylor. 2013. "Support for New Career Academics: An Integrated Model for Research Intensive University Business and Management Schools.” Studies in Higher Education 38(6): 827-840.

Ball, S. J. 2012. "Performativity, Commodification and Commitment: An I-spy Guide to the Neoliberal University.” British Journal of Educational Studies 60(1): 17-28.

Barrett, L., and P. Barrett. 2011. "Women and Academic Workloads: Career Slow Lane or Cul-de-Sac." Higher Education 61(2): 141-55.

Bammer, G. 2008. "Enhancing Research Collaborations: Three Key Management Challenges." Research Policy 37(5): 875-887.

Beaver, D., and R. Rosen. 1979. "Studies in Scientific Collaboration Part III. Professionalization and the Natural History of Modern Scientific Coauthorship." Scientometrics 1(3): 231-245.

Berg, M., and B. Seeber, B. 2016. Slow Professor: Challenging the Culture of Speed in the Academy. University of Toronto Press.

Berman, J. 2008. "Connecting with Industry: Bridging the Divide”. Journal of Higher Education Policy and Management 30(2): 165-174. 
Birnholtz, J.P. 2007. "When Do Researchers Collaborate? Toward a Model of Collaboration Propensity." Journal of the Association for Information Science and Technology 58(14): 2226-2239.

Bogt, H. J., and R. W. Scapens. 2012. "Performance Management in Universities: Effects of the Transition to More Quantitative Measurement Systems.” European Accounting Review 21(3): 451-97.

Bozeman, B., and E. Corley. 2004. "Scientists' Collaboration Strategies: Implications for Scientific and Technical Human Capital.” Research Policy 33(4): 599-616.

Butler, N., and S. Spoelstra. 2014. "The Regime of Excellence and the Erosion of Ethos in Critical Management Studies.” British Journal of Management 25(3): 538-550.

CABS. 2015. “Academic Journal Guide.” Chartered Association of Business Schools, https://charteredabs.org/academic-journal-guide-2015/, accessed on $13^{\text {th }}$ Sept 2017.

Cadez, S., Dimovski, V., and M.Z. Groff. 2017. "Research, Teaching and Performance Evaluation in Academia: The Salience of Quality." Studies in Higher Education 42(8): 14551473 .

Cheek, J. 2008. "Researching Collaboratively: Implications for Qualitative Research and Researchers". Qualitative Health Research 18(11): 1599-1603.

Christensen, T. and P. Lægreid. 2007. Transcending New Public Management: The Transformation of Public Sector Reforms. Aldershot: Ashgate.

Chubb, J., and R. Watermeyer. 2017. “Artifice or Integrity in the Marketization of Research Impact? Investigating the Moral Economy of (Pathways to) Impact Statements within Research Funding Proposals in the UK and Australia." Studies in Higher Education 42(12): 2360-2372.

Clarke, C.A., and D. Knights. 2015. "Careering Through Academia: Securing Identities or Engaging Ethical Subjectivities?” Human Relations 68(12): 1865-1888.

CWTS Leiden Ranking. 2017. "Indicators.” Universiteit Leiden Centre for Science and Technology Studies, http://www.leidenranking.com/information/ indicators, accessed on $05^{\text {th }}$ 
February 2018.

Davies, A., and R. Thomas. 2002. "Managerialism and Accountability in Higher Education:

The Gendered Nature of Restructuring and the Costs of Academic Service." Critical Perspectives on Accounting 13: 179-193.

De Vita, G., and P. Case. 2016. “"The Smell of the Place': Managerialist Culture in Contemporary UK Business Schools.” Culture and Organization 22(4): 348-364.

Deem, R., S. Hillyard, and M. Reed. 2007. Knowledge, Higher Education, and the New Managerialism. Oxford: Oxford University Press.

Engwall, 1. 2007. "Universities, the State and the Market: Changing Patterns of University Governance in Sweden and Beyond." Higher Education Management and Policy 19(3): 87104.

Engstrom, J.L. 1984. "University, Agency and Collaborative Models for Nursing Research: An Overview.” Image: The Journal of Nursing Scholarship 16(3): 76-80.

Fernando, W.D.A. 2016. "Exploring Character in the New Capitalism: A Study of Mid-level Academics' in a British Research-Intensive University." Studies in Higher Education, 1-13. doi: 10.1080/03075079.2016.1212327.

Gill, R. 2014. “Academics, Cultural Workers and Critical Labour Studies.” Journal of Cultural Economy 7(1): 12-30.

Gordon, C. 1991. “Governmental Rationality: An Introduction.” In The Foucault Effect. Studies in Governmentality, edited by G. Burchell, C. Gordon, and P. Miller, 1-52. London: Harvester Wheatsheaf.

Harvie, D. 2004. "Commons and Community in the University: Some Notes and Some Examples." The Commoner 10.

Jeanes, E., B. Loacker, and M. Śliwa. 2014. "Researcher Collaboration: Learning from Experience." In Critical Management Research. Reflections from the Field, edited by E. Jeanes, and T. Huzzard, 41-60. London: Sage.

John-Steiner, V. 2000. Creative Collaboration. New York: Oxford University Press. 
Kallio, K.-M., T.J. Kallio, J. Tienari, and T. Hyvönen. 2015. "Ethos at Stake: Performance Management and Academic Work in Universities." Human Relations 69(3): 685-709.

Katz, J.S., and B.R. Martin. 1997. "What is Research Collaboration?” Research Policy 26(1):1-18.

Knobel, M., T.P. Simões, and C. Henrique de Brito Cruz. 2013. "International Collaborations between Research Universities: Experiences and Best Practices.” Studies in Higher Education 38(3): 405-424.

Lather, P. 1991. Getting Smart: Feminist Research and Pedagogy with/in the Postmodern. New York: Routledge.

Laudel, G., and J. Gläser. 2008. "From Apprentice to Colleague: The Metamorphosis of Early Career Researchers." Higher Education 55(3): 387-406.

Leahey, E., and R.C. Reikowsky. 2008. "Research Specialization and Collaboration Patterns in Sociology." Social Studies of Science 38(3): 425-440.

Leathwood, C., and B. Read. 2013. "Research Policy and Academic Performativity:

Compliance, Contestation and Complicity." Studies in Higher Education 38(8): 1162-1117.

Leišytè, L. 2016. "New Public Management and Research Productivity - a Precarious State of Affairs of Academic Work in the Netherlands." Studies in Higher Education 41(5): 828-846.

Liao, C.H., and H.R. Yen. 2012. "Quantifying the Degree of Research Collaboration: A Comparative Study of Collaborative Measures.” Journal of Informetrics 6(1): 27-33.

Lynch, K. 2015. “Control by Numbers: New Managerialism and Ranking in Higher Education." Critical Studies in Education 56(2): 190-207.

Macfarlane, B. 2017. "The Ethics of Multiple Authorship: Power, Performativity and the Gift Economy." Studies in Higher Education 42(7): 1194-1210.

Melin, G. 2000. "Pragmatism and Self-organization: Research Collaboration on the Individual Level". Research Policy 29(1): 31-40. 
Merton, R. 1973. "The Matthew Effect in Science (originally published in 1968)." In The Sociology of Science: Theoretical and Empirical Investigations, edited by N. W. Storer, 43959. Chicago: University of Chicago Press.

Morrison, P.S., G. Dobbie, and F.J. McDonald. 2003. "Research Collaboration among University Scientists.” Higher Education Research and Development 22(3): 275-296.

Musselin, C. 2005. Le Marché des Universitaires. Paris: Science Po.

Müller-Camen, M., and S. Salzgeber. 2005. "Changes in Academic Work and the Chair Regime:

The Case of German Business Administration Academics.” Organization Studies 26(2): 271-290.

Nielsen, M. W. 2017. "Gender Consequences of a National Performance-based Funding Model: New Pieces in an Old Puzzle.” Studies in Higher Education 42(6): 1033-1055.

Nikunen, M. 2012. "Changing University Work, Freedom, Flexibility and Family." Studies in Higher Education 37(6): 713-729.

Nygaard, L.P. 2017. "Publishing and Perishing: An Academic Literacies Framework for Investigating Research Productivity." Studies in Higher Education 42(3): 519-532.

O’Connor, P., and O'Hagan, C. 2016. “Excellence in University Academic Staff Evaluation: A Problematic Reality?" Studies in Higher Education 41(11): 1943-1957.

Ritchie, S.M., and D.L. Rigano. 2007. "Solidarity through Collaborative Research.” International Journal of Qualitative Studies in Education 20(2): 129-150.

Rossiter, M.W. 1993. “The Matthew Matilda Effect in Science.” Social Studies of Science 23(2): 325-341.

Sander, N. 2012. Das Akademische Prekariat. Leben zwischen Frist und Plan. Konstanz: UVK.

Sherry, S. B., P.L. Hewitt, D.L. Sherry, G.L. Flett, and A.R. Graham. 2010. "Perfectionism Dimensions and Research Productivity in Psychology Professors: Implications for Understanding the (mal)Adaptiveness of Perfectionism." Canadian Journal of Behavioural Science/Revue canadienne des sciences du comportement 42 (4): 273-83. 
Shore, S., and J. Groen. 2009. “After the Ink Dries: Doing Collaborative International Work in Higher Education." Studies in Higher Education 34(5): 533-546.

Smith, D. (2001). "Collaborative Research: Policy and the Management of Knowledge Creation in UK Universities.” Higher Education Quarterly 55(2): 131-157.

Smith, K. 2012. "Fools, Facilitators and Flexians: Academic Identities in Marketised Environments." Higher Education Quarterly 66(2): 155-173.

Stanley, L., and S. Wise. 1983. Breaking Out: Feminist Consciousness and Feminist Research. London: Routledge and Kegan Paul.

Thomas, R., J. Tienari, A. Davies, and S. Meriläinen. 2009. “Let's Talk about 'Us': A Reflexive Account of a Cross-Cultural Research Collaboration." Journal of Management Inquiry 18(4): 313-324.

Välimaa, J. 2015. "Why Finland and Norway still Shun University Tuition Fees - even for International Students." ScienceNordic $22^{\text {nd }}$ February, http://sciencenordic.com/why-finlandand-norway-still-shun-university-tuition-fees---even-international-students, accessed on $13^{\text {th }}$ September 2017.

Welte, H., M. Auer, and C. Meister-Scheytt. 2006. Management von Universitäten. Zwischen Tradition und (Post-)Moderne. München/Mering: Rainer Hampp Verlag.

Willmott, H. 2011. "Journal List Fetishism and the Perversion of Scholarship: Reactivity and the ABS list." Organization 18(4): 429-442.

Ylijoki, O-H. 2013. "Boundary-work Between Work and Life in the High-Speed University." Studies in Higher Education 38(2): 242-255.

Ylijoki, O.-H., and L. Henriksson. 2017. "Tribal, Proletarian and Entrepreneurial Career Stories: Junior Academics as a Case in Point." Studies in Higher Education 42(7) 1292-1308. 